1 Rains AJH, Ritchie HD. Bailey E Love's Short practice of surgery, 19th edn. London: HK Lewis \& Co Ltd, 1984; p 904 .

2 Lawrence WW. Current surgical diagnosis and treatment. Los Atlos: Lange Medical Publication, 1985; p 32.

3 Wyatt AP. Diagnosis and management of acute pancreatitis. Ann Coll Surg Engl 1974; 54: 299.
4 Robinson RO, Stott R. Medical emergencies, 5th edn. London: Butterworth, 1987; pp 116-9.

5 Leese T, Shaw D, Holliday M. Prognostic markers in acute pancreatitis: can pancreatic necrosis be predicted? Ann $R$ Coll Surg Engl 1988; 70: 227-32.

\title{
An intra-abdominal tumour
}

\author{
A Rehm, RJ Williams
}

A 51-year-old man presented with a 30-month history of intermittent episodes of breathlessness, dizziness, headaches, palpitations and sweating. In addition, there had been two episodes during which he fainted due to the severity of his symptoms. After the first episode in September 1993 he consulted a general practitioner who diagnosed hypertension and started treatment with lacidipine. Over the following 14 months his symptoms increased in frequency and severity so that he became afraid to leave his house. In November 1994 he consulted a second general practitioner because of the severity of his symptoms and his blood pressure was found to be 180/ $100 \mathrm{mmHg}$. The treatment was changed to nifedipine but the blood pressure remained elevated. The treatment was therefore modified to bendrofluazide, captopril and lacidipine and he was referred to a consultant physician. The clinical findings revealed a heart rate of 80 beats $/ \mathrm{min}$ (sinus rhythm), a supine blood pressure of $170 / 110 \mathrm{mmHg}$ and an erect pressure of 160/ $100 \mathrm{mmHg}$. No other clinical abnormality was noted.

The following investigations were normal: chest X-ray, electrocardiogram, full blood count, urea, electrolytes and liver function tests. An abdominal ultrasound showed a normal left kidney but the right was absent. One out of two 24-hour urine collections showed a total metadrenaline of $7.9 \mu \mathrm{mol} / \mathrm{specimen}$ (normal range: $0-6.0 \mu \mathrm{mol} / \mathrm{specimen}$ ). Three further 24-hour urine collections revealed normal levels of noradrenaline. Serum noradrenaline was normal. An abdominal computed tomography (CT) scan was arranged (figure 1).

\section{Department of Surgery, \\ North Manchester General Hospital, Delaunays Road, Crumpsall, Manchester M8 6RB, UK \\ A Rehm RJ Williams}

\section{Correspondence to} Mr A Rehm, 7 Guildford Grove, London SE10 8JY, UK

Accepted 29 March 1996

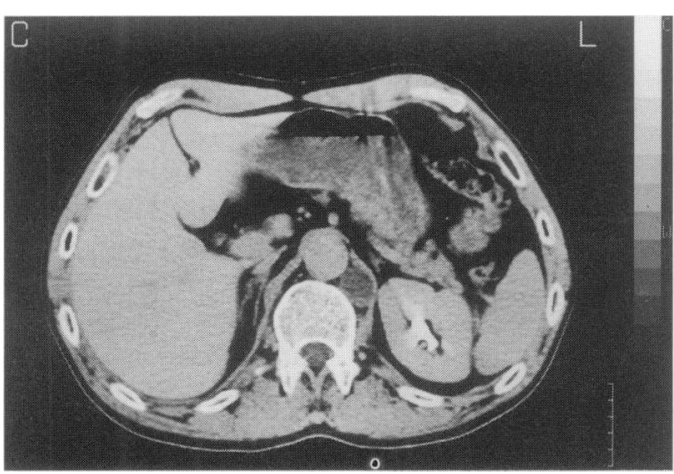

\section{Questions}

1 Which abnormality does the CT scan in figure 1 show?

2 What is the most probable diagnosis considering the case history and clinical findings?

Figure 1 Abdominal CT scan 


\section{Answers}

\section{QUESTION 1}

The CT scan shows a $8 \times 1.5 \mathrm{~cm}$ tubular retrocrural mass on the left side of the vertebral column at the level of the left kidney.

\section{QUESTION 2}

A non-catecholamine-secreting paraganglioma.

A repeat ultrasound scan further confirmed the presence of a solid tumour and did not record vascular flow within it. A meta-iodobenzyl guanidine (MIBG) scan showed no uptake in this region. He was referred for a surgical opinion. It was considered that the lesion may have been a non-catecholaminesecreting paraganglioma. On the basis that approximately $10 \%$ of such lesions are malignant, it was decided to explore the tumour surgically. The patient underwent laparatomy and the tumour was excised from behind the left crus (figure 2). The left adrenal gland was normal. The blood pressure remained stable at $140 / 80 \mathrm{mmHg}$ throughout the procedure. Histology revealed a benign vascular malformation. Two months postoperatively the blood pressure remained elevated at $170 / 100 \mathrm{mmHg}$ in the sitting and $165 / 115 \mathrm{mmHg}$ in the standing position.

\section{Discussion}

Phaeochromocytomas are rare catecholamineproducing tumours occurring in around $0.5 \%$ of all hypertensive patients. They arise from adrenomedullary $(90 \%)$ or extra-adrenal $(10 \%)$ chromaffin cells and are located in the abdomen in $99 \%$ of cases, most often in the

Figure 2 Photograph taken intra-operatively showing the left retrocrural tumour (1) after the crus (2) was divided in relation to the left adrenal gland (3) and the pancreas (4) retroperitoneum near the kidneys in close association with the sympathetic trunks. In $10 \%$ of cases they are familial, $10 \%$ are bilateral and $10 \%$ are malignant. Those arising from extra-adrenal cells are called paragangliomas. Most phaeochromocytomas secrete adrenaline, noradrenaline or dopamine but paragangliomas usually only produce noradrenaline. Those which secrete catecholamines commonly present with paroxysmal or sustained hypertension $(80-95 \%)$, headaches $(60-80 \%)$, sweating $(52-71 \%)$, palpitations $(50-64 \%)$, pallor $(43 \%)$ and anxiety $(30 \%)$. A paroxysm may be precipitated by any movement that disturbs the abdominal contents. Orthostatic hypotension is also present in many patients. In less than $5 \%$ the tumours release large amounts of adrenaline causing hypotension rather than hypertension. ${ }^{1-4}$

\section{INVESTIGATIONS}

Measurement of catecholamines or catecholamine metabolites (4-hydroxy 3-methoxy mandelic acid/vanilylmandelic acid and metanephrines) in 24-h urine collections is the most reliable biochemical test for phaeochromocytoma. Plasma catecholamine can be measured but the episodic nature of its secretion in some patients makes this less useful. Elevated values should be confirmed by at least one repeat measurement. Supportive biochemical findings are hyperglycaemia and polycythaemia. Once a phaeochromocyto$\mathrm{ma}$ is suspected it is necessary to localise the lesion using ultrasound, CT and/or magnetic resonance imaging (MRI). CT scanning is able to detect tumours of $0.5 \mathrm{~cm}$ in diameter with an accuracy of $90 \%$. Multiple lesions have to be excluded. Hormonally active tumours may be located by ${ }^{131} \mathrm{I}-\mathrm{MIBG}$ scintigraphy which has a sensitivity and specificity of $90 \%$ and $99 \%$, respectively. Normal adrenal glands are not shown on the scintigrams. ${ }^{5,6}$ Selective adrenal arteriography or selective vena caval catheterization with venous sampling for catecholamines are rarely employed. ${ }^{1}$ Diagnosis of a catecholamine-secreting phaeochromocytoma may be difficult because total urinary catecholamine and its metabolite levels may be increased only little, if at all. ${ }^{7}$

\section{TREATMENT}

Surgical excision of the tumour is the treatment of choice unless medical contraindications to surgery are present or the patient has widespread metastatic disease from a malignant phaeochromocytoma. Seven to 10 days pre-operatively the patient is started on the alpha-receptor blocker phenoxybenzamine to control blood pressure and restore the blood volume which has been depleted by excessive catecholamines. Doses as high as $150 \mathrm{mg} /$ day may be necessary. A beta-blocker such as propranolol may be added to reduce tachycardia. The tumour is usually approached through a transabdominal approach. Phentolamine or nitroprusside and propranolol should be available to treat sudden hypertension or cardiac dysrrhythmias caused by handling of the tumour during the operation. ${ }^{1}$ 
In our case, the history, clinical findings, negative biochemistry and CT and MIBG scans indicated that the lesion might be a non-catecholamine-secreting paraganglioma. The final diagnosis of a vascular malformation was unexpected but revealed an interesting differential diagnosis of a rare pathology. Retroperitoneal vascular malformations of the choledochus, kidney and pancreas have been described but are rare conditions which may

1 Landsberg L, Young JB, Phaeochromocytoma. In: Wilson JD, Foster D, eds. Williams textbook of endocrinology, 8th edn. Philadelphia: WB Saunders, 1992; pp 668-80.

2 Ross EJ, Griffith DNW. The clinical presentation of phaeochromocytoma. Qf Med 1989; 71: 485-96.

Huddle KR, Mannell A, James MF, Plant ME. Phaeochromocytoma. S Afr Med f 1991; 79: 217-20.

4 Frewin DB, Jamieson GG, Russell WJ, et al. Extra-adrena phaeochromocytoma: report of three interesting cases. Aust NZ F Surg 1989; 59: $691-5$.

5 Khafagi FA, Mortimer RH, Egerton-Vernon JM, PerryKeene DA. Role of 131-I-metaiodobenzylguanidine in the localization of suspected phaeochromocytomas. Med $\mathcal{F}$ Aust 1989; 150: 639-44. cause digestive or urinary tract bleeding. ${ }^{8}$ In this case the symptoms were unrelated to the excised lesion.

\section{Final diagnosis}

Benign vascular malformation.

Keywords: paraganglioma, vascular malformation

6 Plouin PF, Chatellier G, Delahousee M, et al. Detection, diagnosis and localization of phaeochromocytoma. Presse Med 1987; 16: $2211-5$

7 Sinclair D, Shenkin A, Lorimer AR. Normal catecholamine production in a patient with a paroxysmally secreting phaeochromocytoma. Ann Clin Biochem 1991; 28: 417-9.

8 Tarkington MA, Matsumoto AH, Dejter SW, Regan JB. Spectrum of renal vascular malformation. Urology 1991; 38: $297-300$

\title{
Ring-enhancing lesions on computed tomography
}

\author{
NS Brid, AG Kulkarni, MM Kale, PJ Shah, SR Yadav
}

A 23-year-old man was admitted with high grade fever and headache for one week, having developed left hemiplegia two days prior to admission. He gave a history of right-sided pleural effusion a year ago that was treated as tubercular effusion. He had, however, discontinued the treatment after a few weeks. He also gave a history of sexual contact with a commercial sex worker. Clinical examination revealed a toxic, febrile, young patient with left hemiplegia but without signs of raised intracranial pressure. Other systems were normal. After preliminary laboratory tests, high doses of broad-spectrum antibiotics were started but the patient's clinical condition deteriorated. A computed tomography (CT) scan of his brain revealed multiple ring enhancing lesions (figures 1 and 2).

Krishna Institute of Medical Sciences, Karad-415 110, (MS), India

Department of

Medicine

NS Brid

AG Kulkarni

MM Kale

PJ Shah

Department of

Neurosurgery

SR Yadav

Correspondence to Dr AG Kulkarni

Accepted 27 June 1996

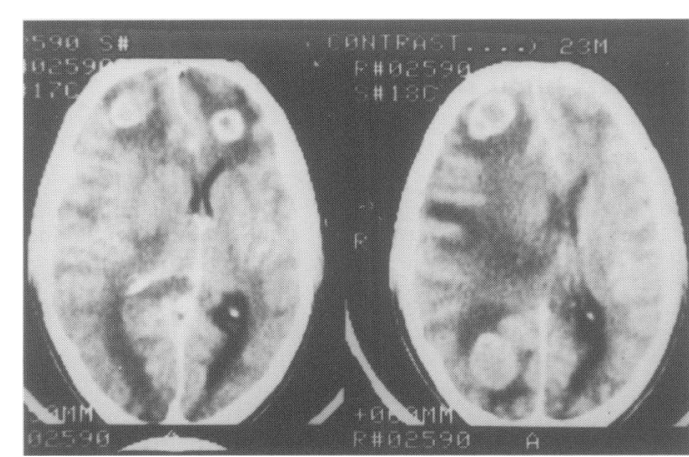

Figure 1 Brain CT scan

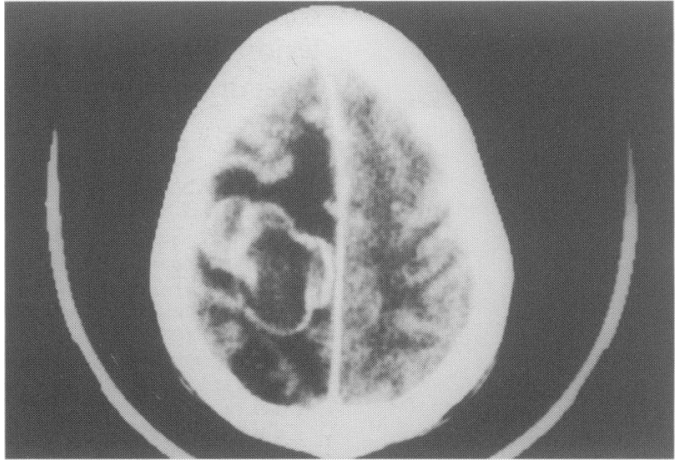

Figure 2 Brain CT scan

\section{Questions}

1 Suggest three causes of these CT appearances.

2 What is the most likely diagnosis in this case? 